\title{
Porcine encephalomyocarditis virus strain BD2 isolated from northern China is highly virulent for $\mathrm{BALB} / \mathrm{c}$ mice
}

\author{
W. YUAN $N^{1,2,3 \#}$, R. HUA ${ }^{4 \#}$,X. ZHANG ${ }^{1,2,3}$, M. SUN ${ }^{1,2,3}$, L. ZHANG ${ }^{1,2,3}$, L. CHEN ${ }^{1,2,3}$, J. SUN ${ }^{1,2,3^{*}}$ \\ ${ }^{1}$ College of Animal Medicine, Agricultural University of Hebei, Baoding, Hebei 071001, P. R. China; ${ }^{2}$ Hebei Engineering and \\ Technology Research Center of Veterinary Biological Products, Baoding, Hebei 071001, P. R. China; ${ }^{3}$ North China Research Center of \\ Animal Epidemic Pathogen Biology, Chinese Ministry of Agriculture, Baoding, Hebei 071001, P. R. China; ${ }^{4}$ State Key Laboratory of \\ Veterinary Biotechnology, Harbin Veterinary Research Institute, Chinese Academy of Agricultural Sciences, Harbin, \\ Heilongjiang 150001, P. R. China
}

Received September 3, 2014; revised March 6, 2015; accepted August 3, 2015

\begin{abstract}
Summary. - Encephalomyocarditis virus (EMCV) can cause acute myocarditis in young pigs or reproductive failure in sows. The BD2 strain was isolated from the suspected piglets with EMCV in China. In order to establish an experimental animal model of EMCV, eight-weeks-old male BALB/c mice were intraperitonealy inoculated with $0.1 \mathrm{ml}$ of $4 \times 10^{5} \mathrm{TCID}_{50}$ suspension of the EMCV. Infected mice demonstrated hind limb paralysis, and movement disorder. The mortality rate of the infected group was $100 \%$ during the one-week observation period. The viral load in the brain of challenged mice gradually increased, with a peak level being $6.53 \log \mathrm{CCID}_{50} / 0.1$ $\mathrm{ml} 5$ days post infection. The pathological injury in infected mice was presented as neuronal necrosis. Brown positive staining could be detected in the cytoplasm of cerebral neurons. These results indicate that the porcine $\mathrm{EMCV}$ isolated from China could replicate in brain tissues and induce acute encephalitis in $\mathrm{BALB} / \mathrm{c}$ mice.
\end{abstract}

Keywords: encephalomyocarditis virus; pathogenicity; mice

\section{Introduction}

Encephalomyocarditis virus (EMCV, the genus Cardiovirus, the family Picornaviridae) is a single-stranded positive-sense RNA virus of approximately $7.8 \mathrm{~kb}$ with a large open reading frame (ORF) (Palmenberg et al., 1984). Rodents are considered as reservoirs or natural hosts of the virus (Zimmermann et al., 1994). Since fatal disease of swine caused by EMCV was first described in 1958 (Murnane et al.,1960), the virus has been recognized worldwide as a pathogen that can infect several host species including pigs, rodents, cattle, elephants, raccoons, marsupials, and primates such as baboons, monkey, chimpanzees, and even humans (Gelmetti et al., 2006; Spyrou et al., 2004).

*Corresponding author. E-mail: vaccine2000@126.com; phone: +86 3127528 377. "W. Yuan and R. Hua contributed equally to this work.

Abbreviations: $\mathrm{EMCV}=$ encephalomyocarditis virus; p.i. $=$ post infection
EMCV strains vary in their pathogenicity and tissue tropism. Each form of the disease in pigs seems to be restricted to certain geographical area (Kim et al., 1989). In domestic pigs, EMCV has been recognized as a cause of acute myocarditis in young pigs or reproductive failure in sows (Dea et al., 1991; Gelmetti et al., 2006; Koenen and Vanderhallen, 1997). EMCV can cause acute neurological disorders, diabetes, or myocarditis in mice or rats, whereas certain porcine strains such as B279/95 and G424/90 generate no visible symptoms after infection (Psalla et al., 2006a,b). Based on organotropism in mice, Craighead classified EMCV into two variants, $\mathrm{E}$ (neurotropic) and $\mathrm{M}$ (myocardiotropic) (Craighead, 1966).

EMCV infection has been confirmed in several pig farms in China by etiology and serology (Ge et al., 2010). The BD2 strain was isolated in northern China from piglets suspected with EMCV in 2010 (Yuan et al., 2014). Aim of this study is to establish an experimental model and analyze the pathogenicity of the BD2 strain in mice for further study of the pathogenic mechanisms of EMCV. 


\section{Materials and Methods}

Cells, virus and mice. BHK-21 cells were used to propagate the virus stock and to determine virus titers in $\operatorname{TCID}_{50}(50 \%$ tissue culture infective dose) assay. Cells were maintained in Dulbecco's modified Eagle medium (DMEM; Invitrogen) supplemented with $10 \%$ fetal bovine serum (FBS; Hyclone Laboratories Inc., USA) at $37^{\circ} \mathrm{C}$ under $5 \% \mathrm{CO}_{2}$. The $\mathrm{BD} 2$ strain was passaged in $\mathrm{BHK}-21$ cells, and the fourth passage was used in this study. Eight-weeksold male $\mathrm{BALB} / \mathrm{c}$ mice were obtained from the Laboratory animal center, Military academy of medical science (China). Animal experiments were approved by the Institutional animal care and ethics committee of Hebei Agricultural University with certificate IACECHEBAU20110509 and animals were maintained according to the International guiding principles for biomedical research involving animals. All animals were free of EMCV, as assessed by serological and virological examinations before inoculation. The mice were randomly assigned to groups in each experiment. Each group was separately kept in a different isolation cage.

Pathogenicity analysis of EMCV BD2 in mice. According to the Reed-Müench method, $\mathrm{LD}_{50}$ of BD2 strain was $4 \times 10^{4} \mathrm{TCID}_{50}$ (data not shown). Ten mice from the infected group were intraperitonealy inoculated with $0.1 \mathrm{ml}$ of the virus suspension containing $4 \times 10^{5}$ $\mathrm{TCID}_{50}$. Ten mice from the control group were mock inoculated with $0.1 \mathrm{ml}$ of the supernatant from the BHK-21 cell culture. The mice were observed for 7 days post infection (p.i.) to determine the survival rates. Viral RNA was extracted from tissue samples including brain, heart, spleen, kidney, lung, and liver. Samples were subjected to RT-PCR with the primer pair F: 5'-CAG AGG CTG ATG TAG ATG AAG TGG C-3' and R: 5'-CAG AAT GCA ATG CTC AAA TGG TGG A-3', to identify the isolates. RT-PCR was established by our laboratory. Briefly, RT-PCR was performed by using $1 \mu$ of diluted RNA template and $10 \mu \mathrm{mol}$ of each primer in a $25 \mu \mathrm{l}$ reaction volume by following the manufacturer's protocol with the following cycling profile: $94^{\circ} \mathrm{C}$ for $3 \mathrm{~min}$ and 30 cycles of $94^{\circ} \mathrm{C}$ for $30 \mathrm{sec}, 56^{\circ} \mathrm{C}$ for $30 \mathrm{sec}$, and $72^{\circ} \mathrm{C}$ for $25 \mathrm{sec}$ and final extension $72^{\circ} \mathrm{C}$ for $5 \mathrm{~min}$. Five microliters of RT-PCR products were analyzed by agarose gel electrophoresis. The size of EMCV fragment amplified by RT-PCR was $425 \mathrm{bp}$.

Virus titer, histology, and immunohistochemistry. Twenty mice in the infected group were inoculated with EMCV BD2 containing $1 \times 10^{5} \mathrm{TCID}_{50}$, as described above. Fifteen of these infected mice were eunthanized 1, 3 and 5 days p.i., and their brain, heart, spleen, kidney, lungs and liver were collected. The virus titers of the homogenated tissue samples were determined in BHK-21 cells and recorded as $\mathrm{CCID}_{50}$ (50\% cell culture infective dose) using the Reed-Müench method. Briefly, cells were prepared in 96-well plates and inoculated with the homogenated brain samples (100 $\mu \mathrm{l} /$ well), which were ten-fold serially diluted. Plates were incubated for 24 to $36 \mathrm{hr}$. Virus titers were determined by the presence of a visible CPE.

The brain, heart, and spleen tissues of five inoculated mice were collected 5 days p.i., fixed in $4 \%$ paraformaldehyde, and embedded in paraffin. The sections of these tissues were stained with hematoxylin and eosin before they were observed under a microscope. EMCV positive cells were detected using a standard two-step technique, with a horseradish peroxidase (HRP)-labeled secondary antibody. A monoclonal antibody (C11) against EMCV VP1 protein was used as the primary antibody, with a dilution of 1:1000. The antibody for the study was supplied by Dr. Ge in China Agricultural University. In detail, deparaffinized brain sections were incubated with $10 \%$ normal goat serum for 30 min to block nonspecific binding. The diluted primary antibody was added and incubated for $1 \mathrm{hr}$ at $37^{\circ} \mathrm{C}$, followed by incubation in a $1: 100$ dilution of HRP-conjugated goat anti-mouse secondary antibody for $30 \mathrm{~min}$ at $37^{\circ} \mathrm{C}$. The slides were subsequently incubated in a 3 , $3^{\prime}$-diaminobenzidine (DAB) substrate; the reaction was stopped by washing with PBS. After dehydration, cover slips were placed on the slides, and examined under light microscope (Olympus).

Statistical analysis. Results were presented as means \pm standard deviations. The significance of variations among the experimental groups was determined by one-way or two-way ANOVA using the GraphPad Priam (version 4.0) software. $P$-values less than 0.05 were considered to be significant.

\section{Results and Discussion}

The pathogenicity of EMCV BD2 was analyzed by inoculation experiments performed with $\mathrm{BALB} / \mathrm{c}$ mice. Observation of clinical symptoms showed that inoculated mice exhibited signs of depression, hunched posture, ruffled fur, lethargy,

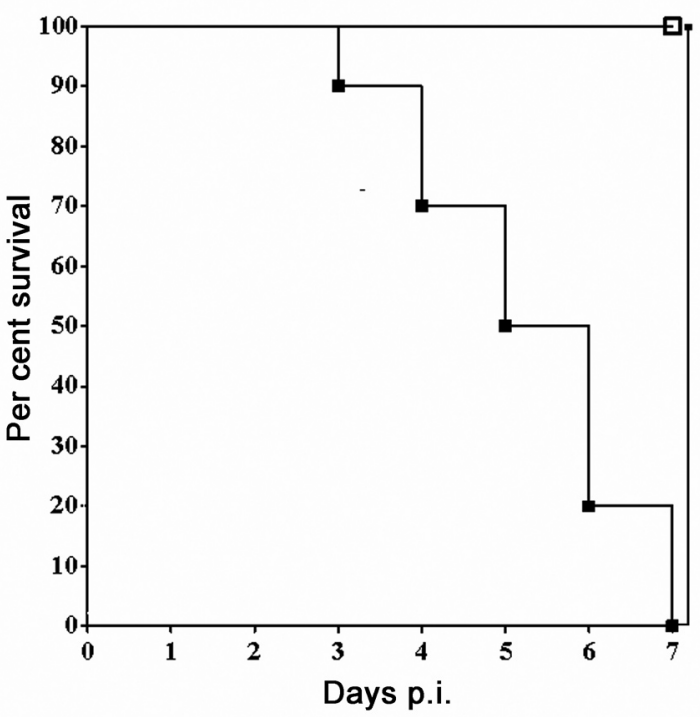

Fig. 1

The survival of the inoculated mice with EMCV BD2

Eight-weeks-old BALB/c mice $(\mathrm{n}=10)$ were intraperitonealy inoculated with $0.1 \mathrm{ml}$ of EMCV BD2 $\left(4 \times 105 \mathrm{TCID}_{50}\right)$ and observed daily for mortality for 7 days. 


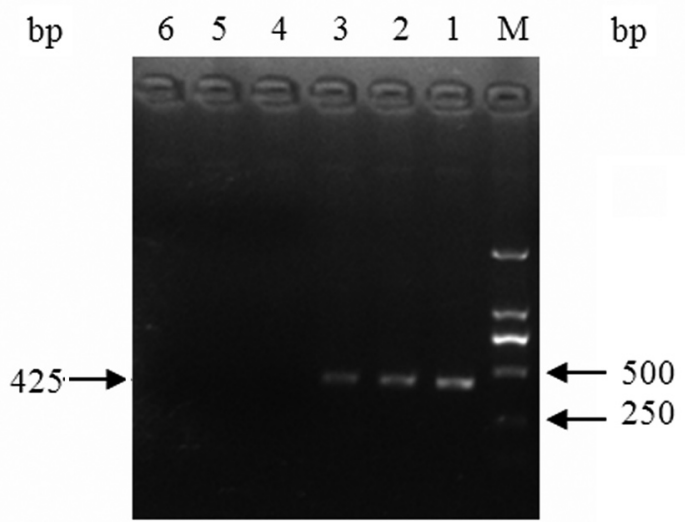

Fig. 2

Detection of EMCV in tissue specimens of mice inoculated with EMCV BD2 by RT-PCR

Lane M: molecular weight markers (DL2000 ladder), lanes 1-6: samples of brain, spleen, heart, kidney, lung, and liver.

and anorexia. The clinical signs lasted for 24 to $48 \mathrm{hr}$ before the mice died, with signs of posterior limb paralysis. All mice inoculated with a $4 \times 10^{5} \mathrm{TCID}_{50}$ died between 3 to 7 days p.i. (Fig. 1). The mortality rate of the mice in the infected group was $100 \%$ after a week of observation. The survival rate of mice infected with virus was significantly higher than that of the uninfected mice $(P<0.001)$. The corresponding virus was identified by RT-PCR from the brain, spleen, and heart of mice that died, but was absent from the kidney, lungs, and liver (Fig. 2). No paralysis was observed in any surviving mice. These data suggest that EMCV BD2 strain was highly virulent for $\mathrm{BALB} / \mathrm{c}$ mice. After infection, $\mathrm{BD} 2$ strain was mainly distributed in the brain, spleen, and heart.

The viral loads of tissue samples from the selected infected mice were assessed by measuring the $\mathrm{CCID}_{50}$ per $0.1 \mathrm{ml}$ of the virus. The mean $\log \left(\mathrm{CCID}_{50} / 0.1 \mathrm{ml}\right)$ values for the viruschallenged mice are shown in Fig. 3. The viral titers in the infected mice were detectable 1 day p.i. in brain, heart, and spleen. In contrast, the viral loads in the kidney, lungs, and liver could not be detected 1, 3 or 5 days p.i. In the brain, the titers gradually achieved higher virus titer with a peak level of $6.53 \log \left(\mathrm{CCID}_{50} / 0.1 \mathrm{ml}\right) 5$ days p.i. The viral loads in the heart and spleen gradually declined 5 days p.i., with a minimum level of 2.80 and $2.47 \log \left(\mathrm{CCID}_{50} / 0.1 \mathrm{ml}\right)$ respectively (Fig. 3). These data indicate that EMCV BD2 strain replicates mainly in the brain tissues of BALB/c mice.

All of the infected mice showed evidence of encephalitis and meningitis, including perivascular infiltration with mononuclear cells and some neuronal degeneration with necrosis (Fig. 4a). Moreover, the positive signals of the viral antigen could be observed in the brain of all the infected mice when viewed under the microscope. Antigen was mainly located in the cytoplasm (Fig. 4b). Neither lesions nor the viral antigen were observed in the heart and spleen. These data further confirmed that brain tissue was the target organ of $\mathrm{BD} 2$ replication.

EMCV strains differ in their pathogenicity and tissue tropism (Carocci and Bakkali-Kassimi, 2012; Craighead, 1966; Spyrou et al., 2004). For preweaned piglet, EMCV can cause acute myocarditis and sudden death. In ICR Swiss male mice, EMCV-B produces no overt illness, EMCVMM produces severe neurological signs followed by death,

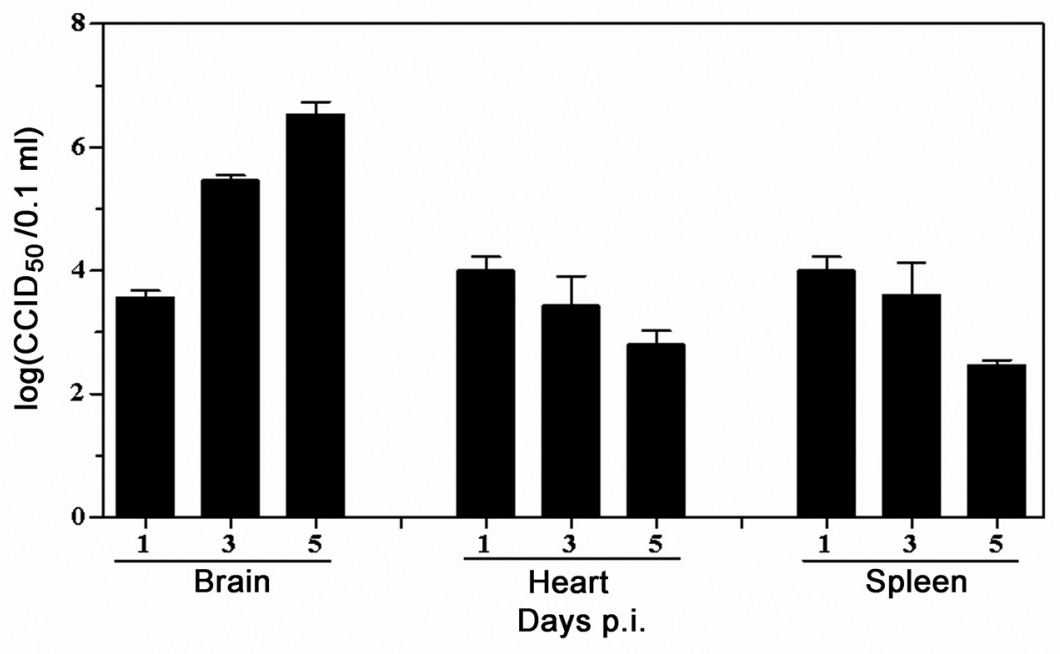

Fig. 3

Viral loads were determined as $\mathrm{CCID}_{50}$ in the brain, heart, and spleen of mice inoculated with EMCV BD2 Eight-weeks-old BABL/c mice $(n=30)$ were inoculated intraperitonealy with $0.1 \mathrm{ml}$ of EMCV BD2 $\left(1 \times 105\right.$ TCID $\left.{ }_{50}\right)$. Tissues were collected 1,3 and 5 days p.i., homogenized, frozen-thawed and assayed for viral titers. 

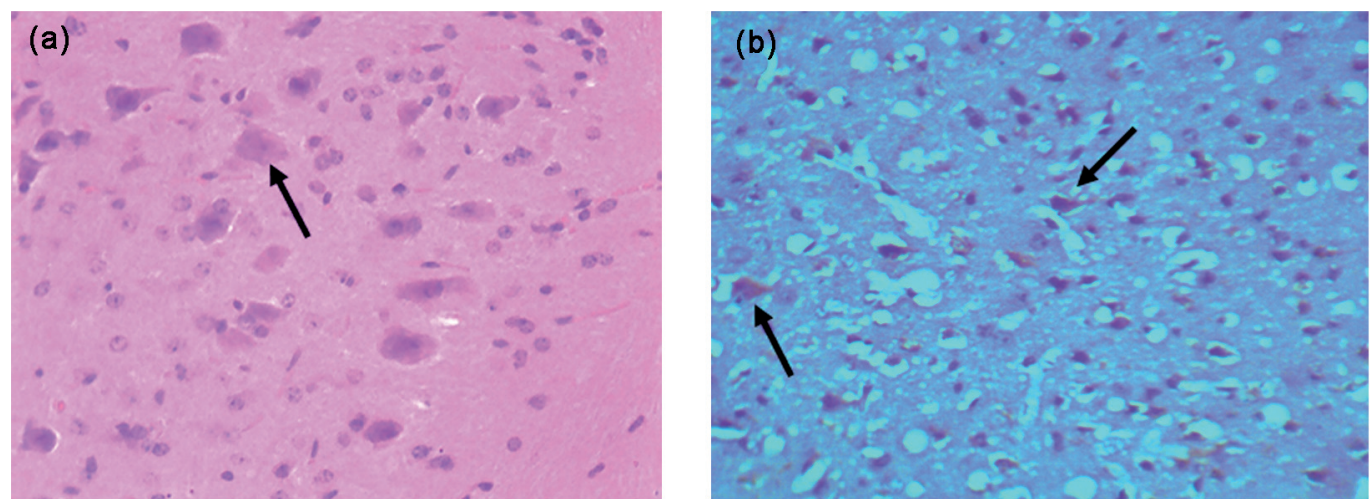

Fig. 4

Hematoxilin-eozin and immunohistochemical staining of brain tissues of the infected mice $(\times 200)$

(a) H.E. staining; (b) immunohistochemical staining. Mice inoculated with EMCV BD2 were sacrificed 5 days p.i. and brain sections were prepared for observing pathological changes and detecting EMCV-antigen positive cells. (a) Virus could cause severe brain damage: necrosis of neurons. Arrow shows necrosis of neurons. (b) The positive signals of the viral antigen could be observed in the brain of all the infected mice. Arrows show the positive signals.

EMCV-D induces a diabetes-like syndrome, and EMCV-K is lethal but produces no overt signs of infection (Cerutis et al., 1989). The mechanisms involved in EMCV tropism and pathogenicity are not fully understood. EMCV has caused great economic loss in almost all pig-breeding countries. EMCV BD2 described in this study was found in dead piglets. Previous findings indicate that the EMCV BD2 isolate could infect piglets but did not show any clinical signs (data not shown). Moreover, EMCV BD2 is highly pathogenic to mice. By contrast, other porcine EMCV strains, such as G424/90 or B279/95, are essentially nonlethal for rats or mice (Psalla et al., 2006a;b). Thus, the results reveal a correlation between the geographic isolation and the genetic type (Koenen and Vanderhallen, 1997). The BD2 isolate belongs to group I, along with strains NJ08, HB1, BJC3, CBNU, K3, K11, BEL-2887A, GX0601, GXLC, pEC9, and PV21, whereas other four strains (D variant, EMCV-B, EMCV-D, and PV2) belong to group II (Yuan et al., 2014). NJ08, BJC3, and BD2 strains were all isolated from piglets in China. Experiments showed that NJ08, BJC3 isolates could cause severe clinical symptoms and pathological changes in mice but no obvious clinical and pathological changes in commercial piglets (Bai et al., 2012; Ma et al., 2008). These findings suggest that BD2 isolate may have similar properties with BJC3 and NJ08. Hind limb paralysis and encephalitis had been observed during EMCV BD2 infection. This indicates that the murine central nervous system was damaged during EMCV infection. Histology and immunohistochemistry examination of inoculated mice tissues confirmed that EMCV BD2 replicates mainly in brain tissues. Due to the role played by rodents as a reservoir for the transmission of the EMCV to pigs (Spyrou et al., 2004), EMCV strain BD2 may be transmitted to pigs from mice.
In summary, in this study we have demonstrated that EMCV BD2 can infect BALB/c mice under experimental conditions. The BD2 strain may, after infection, mainly replicate in brain tissues, induce acute encephalitis, and eventually cause death. This experimental model can be used for further study of the pathogenic mechanisms for porcine encephalomyocarditis virus.

Acknowledgements. This work was supported partly by Science and Technology Project Foundation of Animal Husbandry Bureau from Hebei province in China (2011-1-09).

\section{References}

Bai J, Jiang K, Zhang G, Wang X, Li Y, Jiang P (2012): Pathogenicity and molecular analysis of an encephalomyocarditis virus isolate from mideastern China. Can. J. Vet. Res. 76, 157-160.

Carocci M, Bakkali-Kassimi L (2012): The encephalomyocarditis virus. Virulence 3, 351-367. http://dx.doi.org/10.4161/ viru. 20573

Cerutis D, Bruner R, Thomas D, Giron D (1989): Tropism and histopathology of the $\mathrm{D}, \mathrm{B}, \mathrm{K}$, and MM variants of encephalomyocarditis virus. J. Med. Virol. 29, 63-69. http:// dx.doi.org/10.1002/jmv.1890290112

Craighead J. (1966): Pathogenicity of the $M$ and $E$ variants of the encephalomyocarditis (EMC) virus. II. Lesions of the pancreas, parotid and lacrimal glands. Am. J. Pathol. 48, 375-386.

Dea S, Bilodeau R, Sauvageau R, Martineau G (1991): Outbreaks in Quebec pig farms of respiratory and reproductive problems associated with encephalomyocarditis virus. J. Vet. Diagn. Invest. 3, 275-282. http://dx.doi. org/10.1177/104063879100300401 
Ge X, Zhao D, Liu C, Wang F, Guo X, Yang H (2010): Seroprevalence of encephalomyocarditis virus in intensive pig farms in China. Vet. Rec. 166, 145-146. http://dx.doi.org/10.1136/ vr.b4766

Gelmetti D, Meroni A, Brocchi E, Koenen F, Cammarata G (2006): Pathogenesis of encephalomyocarditis experimental infection in young piglets: a potential animal model to study viral myocarditis. Vet. Res. 37, 15-23. http://dx.doi. org/10.1051/vetres:2005041

Kim H, Christianson W, Joo H (1989): Pathogenic properties of encephalomyocarditis virus isolates in swine fetuses. Arch. Virol. 109, 51-57. http://dx.doi.org/10.1007/ BF01310517

Koenen F, Vanderhallen H (1997): Comparative study of the pathogenic properties of a Belgian and a Greek encephalomyocarditis virus (EMCV) isolate for sows in gestation. Zentralbl Veterinarmed B. 44, 281-286. http://dx.doi. org/10.1111/j.1439-0450.1997.tb00974.x

Ma L, Ge X, Zhang J, Zhao T, Chen Y, Yang H, Guo, X. (2008): Pathogenicity analysis of Chinese isolates of porcine encephalomyocarditis virus. Chinese J. Vet. Medicine $44,20-21$.

Murnane T, Craighead J, Mondragon H, Shelokov A (1960) Fatal disease of swine due to encephalomyocarditis virus. Science 131, 498-499. http://dx.doi.org/10.1126/ science.131.3399.498

Palmenberg A, Kirby E, Janda M, Drake N, Duke G, Potratz K, Collett M (1984): The nucleotide and deduced amino acid sequences of the encephalomyocarditis viral polyprotein coding region. Nucleic. Acids Res. 12, 2969-2985. http:// dx.doi.org/10.1093/nar/12.6.2969

Psalla D, Psychas V, Spyrou V, Billinis C, Papaioannou N, Vlemmas I (2006a): Pathogenesis of experimental encephalomyocarditis: a histopathological, immunohistochemical and virological study in mice. J. Comp. Pathol. 135, 142-145. http://dx.doi.org/10.1016/j.jcpa.2006.04.003

Psalla D, Psychas V, Spyrou V, Billinis C, Papaioannou N, Vlemmas I (2006b): Pathogenesis of experimental encephalomyocarditis: a histopathological, immunohistochemical and virological study in rats. J. Comp. Pathol. 134, 30-39. http://dx.doi.org/10.1016/j.jcpa.2005.06.008

Spyrou V, Maurice H, Billinis C, Papanastassopoulou M, Psalla D, Nielen M, Koenen F, Papadopoulos O (2004): Transmission and pathogenicity of encephalomyocarditis virus (EMCV) among rats. Vet. Res. 35, 113-122. http://dx.doi. org/10.1051/vetres:2003044

Yuan W, Song Q, Zhang X, Zhang L, Sun J (2014): Isolation and molecular analysis of porcine encephalomyocarditis virus strain BD2 from northern China. Infect Genet. Evol. 21, 303-307. http://dx.doi.org/10.1016/j. meegid.2013.11.014

Zimmermann A, Nelsen-Salz B, Kruppenbacher J, Eggers H (1994): The complete nucleotide sequence and construction of an infectious cDNA clone of a highly virulent encephalomyocarditis virus. Virology 203, 366-372. http://dx.doi. org/10.1006/viro.1994.1495 